\title{
HEREDITY AND CRIME: BAD GENES OR BAD RESEARCH?*
}

\author{
GLENN D. WALTERS \\ THOMAS W. WHITE \\ U.S. Penitentiary \\ Leavenworth, Kansas
}

This review of the research literature on the heritability of criminal behavior organizes the studies by four basic research methodologies: family studies, twin studies, adoption studies, and gene-environment interaction studies. Interpretation of the relationships observed in these studies is made ambiguous and problematic by critical methodological inadequacies in the research itself. The methodological flaws notwithstanding, the research evidence does seem to suggest the existence of a fairly consistent relationship between heredity and criminal behavior. Recommendations concerning the future direction of research in this area are discussed.

The notion that certain personality characteristics are inherited, albeit controversial, is certainly an intriguing possibility. Rowe (1987), however, argues that genetic factors have been largely ignored by personality psychologists because they run counter to the zeitgeist, which holds that environmental factors are preeminent in personality development. He states further that various research findings, such as the convergence of development for twins raised apart and the divergence of development for adopted siblings raised together, point to the importance of genetic factors in human personality. Rowe concludes by noting that a spirit of cooperation, rather than competition, between behavioral geneticists and personality psychologists would benefit both disciplines.

One need only scan the literature on heredity and personality to see that there is substance to Rowe's argument. Results from several studies indicate that heredity may account for as much as $50 \%$ of the variance in scores achieved on various measures of personality (Dworkin et al., 1976; Goldsmith, 1983; Loehlin et al., 1985; Rushton et al., 1985, 1986). Rushton et al. (1986), for instance, found heritability estimates of 56 to $72 \%$ on questionnaires measuring aggression, altruism, assertiveness, empathy, and nurturance, and Dworkin et al. (1976) observed evidence of heritability on

- The authors would like to thank anonymous reviewers of earlier drafts of this manuscript for their helpful comments. The assertions contained herein are the private views of the authors and should not be construed as official or as reflecting the views of the Department of Justice or the Federal Bureau of Prisons. 
several Minnesota Multiphasic Personality Inventory scales. A logical extension of this research would be to investigate the heritability of certain types of social behavior, including criminality.

Over 25 studies on the genetics of crime have been published since Rosenthal's (1975) review of the research in this area. In addition to the interest scientists have in examining the proposed link between heredity and crime, this research has important social, political, and treatment implications (Mednick, 1987). When one considers the financial and emotional impact criminals have on society (Flanagan and McGarrell, 1986), efforts to understand the causes of crime take on added meaning. Over the years numerous theories have been proposed to account for criminal behavior, but the vast majority have come and gone with little actual impact on the crime rate or our understanding of criminals. Thus, a theory that postulates that genetic factors are important in the development of criminality, while highly controversial, holds promise of advancing our understanding of this very costly and perplexing problem. Regarding this last point, Wilson and Herrnstein (1985:103) conclude their chapter on constitutional factors in criminal behavior by stating that "crime cannot be understood without taking into account individual predispositions and their biological roots."

Lombroso (1918) was one of the first investigators to assess the possible connection between heredity and crime. After conducting thousands of postmortem studies on prison convicts, Lombroso concluded that these individuals were actually throwbacks to an earlier stage in man's development as evidenced by their slanting foreheads and large, protruding jaws. In this atavistic theory of criminality, the criminal was viewed as following a genetic blueprint of continued social violation over which he had very little control. This first attempt at studying the question of crime and heredity met with strident criticism from both the medical and sociologic communities (see Yochelson and Samenow, 1976).

Sheldon (1942) is often credited with developing the first systematic genetic theory of criminality. Basing his theoretical speculations on the relationships he observed between various body types and personality styles, Sheldon argued that certain body types were not only associated with, but actually responsible for, the development of specific personality styles and temperaments. For instance, he found that the muscular mesomorphic male was more prone to criminality than men with other types of body build. Sutherland (1951) criticized Sheldon for using ambiguously defined delinquent groups, scoring methods that were subjective and unreliable, and categories that overlapped significantly. The primary difficulty with Sheldon's approach, however, relates to the most fundamental of methodological maxims, namely, that correlation does not imply causation.

A new consideration was introduced into the genetic research on criminality with the discovery of the XYY sex chromosome in the early 1960s 
(Sandberg et al., 1961). Males possessing this chromosomal anomaly were thought to be taller, more severely afflicted with acne, less intelligent, more physically aggressive, and more likely to be found in prisons or mental hospitals compared with normal XY males (see Jarvik et al., 1973). After reviewing the rapidly accumulating body of literature on the XYY male, Owen (1972) found that other than increased physical stature, there was very little support for any of the commonly held beliefs about these individuals, particularly in terms of their propensity for crime and violence. Even if a consistent relationship did exist between this chromosomal abnormality and criminal behavior, further investigations in this area would probably not aid much in our efforts to understand the heritability of crime because the XYY genome is so rare (1 or 2 per 1,000 male births; see Jarvick et al., 1973) that it could not possibly account for the level of serious criminality currently prevailing.

Since Lombroso, Sheldon, and Sandberg et al., there has been a continued interest in the biological bases of criminal behavior. In their book Crime and Human Nature, Wilson and Herrnstein (1985) address contemporary issues concerning the possibility of an association between heredity and crime. Based on their examination of the evidence, Wilson and Herrnstein conclude that the negative reception the crime-gene hypothesis has received in many quarters is unfounded and that a connection does in fact exist between heredity and various measures of criminality. In this review we investigate the crime-gene hypothesis in even greater detail than did Wilson and Herrnstein, our goal being to answer the question posed by our title: Bad genes or bad research?

\section{METHODOLOGICAL ISSUES IN RESEARCH ON HEREDITY AND CRIME}

As with past attempts to link biological anomaly with criminality, current research examining the relationship between genetics and crime is replete with serious methodological oversights, inconsistent data collection practices, and fundamental problems of analysis and exposition. Thus, prior to reviewing the current research literature on crime and heredity, we discuss some general methodological issues relevant to research in this area. The issues raised, however, are applicable to all forms of genetic research into human behavior, not just studies of heredity and crime, and not all genetic investigations suffer from each and every one of the limitations delineated below.

\section{DEFINITIONS OF CRIMINALITY}

Criminality has been defined in different and sundry ways by researchers scrutinizing the relationship between genetics and crime. Several studies, for example, have defined criminality on the basis of a single arrest (Crowe, 1972); others have defined it on the basis of at least one prior conviction 
(Hutchings and Mednick, 1975); still others have relied on a diagnosis of antisocial personality rather than actual criminal behavior per se (Cadoret, 1978). Based on these varying criteria, a single arrest for auto theft in one study is equivalent to several prior convictions for robbery and murder in a second study, and both could be comparable to a diagnosis of antisocial personality in a third study. Though researchers in this area do not appear concerned about the use of such vastly discrepant criterion measures, it seems obvious that robust, replicable results are unlikely when such widely divergent criteria are employed. Moreover, the lack of a consistent definition has permitted the inclusion of virtually any type of illegal behavior into some researchers' data analyses, thereby potentially inflating the reported occurrence of criminality. Although there is nothing intrinsically wrong with using a diagnosis such as sociopathy or antisocial personality in lieu of a legal definition of criminality, such diagnoses should be precise, replicable, and refer to actual criminal involvement. In our view, it would be more meaningful to conceptualize criminality in terms of lifestyle, i.e., as a life pattern involving repeated criminal violation and blatant disregard for the rights of others.

\section{DETERMINING ZYGOSITY}

In studies of twins, establishing whether a pair of twins is monozygotic (MZ) or dizygotic (DZ) can have an important impact on the results one achieves. Despite conventional wisdom, monozygotic twins are not always identical in appearance and not all identical-looking twins are monozygotic. Consequently, photographs, measures of physical appearance, and procedures like Siemen's (1924) similarity method sometimes yield less than accurate results relative to a diagnosis of zygosity, although this is much less of a problem in studies using sufficiently sized samples. Moreover, the results of one study found $95 \%$ agreement between questionnaire-based diagnoses and blood/serum findings (Nichols and Bilbro, 1966). The most reasonable approach to determining zygosity would appear to be to use blood and serum typing or to restrict one's analyses to pairs for whom zygosity can be reliably determined through an inspection of physical characteristics.

\section{DATA SOURCE}

Estimates of criminality can be based on retrospective analyses, review of official records, or interpretation of interview data. Although there are potential problems with each of these procedures, the retrospective approach probably yields the most biased results and should be avoided whenever possible (Weissman et al., 1986). In several of the genetic studies on crime, however, retrospective analysis has been a primary method of data collection, and this should be considered in interpreting the results. 


\section{CONTROL OR COMPARISON GROUPS}

The sine qua non of good research is randomization and the use of an appropriate control group (Kerlinger, 1973). Randomization is often not possible when conducting research in naturalistic settings, but there is usually nothing to prevent investigators from using an appropriate control or comparison group. Researchers may decide to use control/comparison subjects who have been matched with the proband ${ }^{1}$ subjects on certain relevant dimensions or consider that portion of a large, unselected sample that does not display the genetic characteristic of interest (e.g., criminal biological parent) as a sort of natural comparison group. Despite the relative ease with which control/comparison groups could be employed, several studies examining the heritability of criminal behavior have failed to use any type of control or comparison condition (e.g., Guze et al., 1967; Zur Nieden, 1951).

\section{SAMPLE SIZE}

Perhaps it goes without saying, but before an association can be discovered, one must use a sample of sufficient size so that the relationship has ample opportunity to surface. Some of the earlier twin studies (e.g., Borgstrom, 1939; LeGras, 1932) evaluated relationships with as few as four twin pairs to a group. Obviously, it is very difficult to draw conclusions from a study in which so few subjects are employed because systematic bias is much more likely to be a factor.

\section{SAMPLING BIAS}

It is possible to have an adequately sized research sample that is nonetheless biased, as happened with some of the earlier research on the prevalence of the XYY chromosomal abnormality among subjects in prisons and mental hospitals. After screening subjects who, from external appearances, looked as if they might possess the XYY chromosome (e.g., tall, light complection, presence of acne or dermatoglyphic alterations), the prevalence of the XYY genome was calculated. Even though the sample sizes used in these calculations were sufficient, the samples were quite obviously inadequate in the sense that they originated from a preselected, potentially biased sample (Owen, 1972). In several of the genetic studies on crime, the subjects included in the data analyses were derived from similarly biased samples and were often selected from larger samples with little or no explanation as to the rationale for their inclusion.

1. A proband is an individual who possesses the trait or characteristic (in this case psychopathy or criminality) in question and so serves as the starting point for an investigation. 


\section{DIFFERENTIAL MORTALITY}

Another aspect of biased sampling is differential mortality. Researchers must ensure that there is not a pattern to the attrition or noncompliance found in a particular sample of subjects, for if such a pattern exists the results obtained may be biased. Representative of this problem, Guze et al. (1967) identified 519 first-degree relatives of a group of 93 convicted male criminals. For various reasons, however, they were only able to interview 260 of those relatives, a mortality rate of $50 \%$. It is therefore possible that very different relationships may have resulted had all 519 relatives been interviewed.

\section{INTERVENING VARIABLES}

It is admittedly impossible to control all of the variables potentially capable of modifying an investigator's findings, but some of the more obvious possibilities should at least be considered. Of the more common intervening variables worthy of note, age, education, sex, race, and social class are probably the ones most logically related to genetic data on crime. In several of the better known adoption studies, however, not only were the relevant variables of social class and early environmental background not controlled, but they may have actually been confounded with the genetic variable (see Van Dusen et al., 1983). Similarly, although Bohman et al. (1982) observed a relationship between heredity and petty criminality, they failed to pursue the corollary finding that criminal offspring had spent significantly more time than noncriminal offspring with their natural mothers prior to being adopted. When such potentially important and logically relevant intervening variables are inadequately investigated, it is difficult to view the findings with anything but skepticism.

\section{AGE AT RISK}

It is well documented that criminals typically begin their life of crime during early adolescence, but actual criminal activity is sometimes not officially recorded until the offender is 18 or 20 years of age (Wirt and Briggs, 1965). There is also research to suggest that important differences exist between juvenile and adult criminality (Klein, 1987). It is therefore important that investigators not mix adolescent and adult populations. Preferably, subjects should be old enough to be at risk (at least 18 to 20 years of age) for documentable adult criminality.

\section{BASE RATES}

As Meehl and Rosen (1955) point out, it is essential for one to know the base rate of a particular behavior before trying to predict that behavior. This is particularly true of research on crime because the base rate of a behavior like crime can differ across naturally occurring groups. If, for instance, we 
examine criminality in twins using an all-male index (MZ and DZ) group and do not control for the sex of the co-twin, we might expect greater concordance for criminality in the monozygotic group (all of the co-twins would be male), as opposed to the dizygotic group (some of the co-twins would probably be female), simply because the base rate for criminality is higher among males than females.

\section{STATISTICAL PROCEDURES}

Of all the methodological issues and criticisms that plague this body of research, none is more salient than that surrounding the use of statistical procedures. A few of the more common statistical problems encountered include the use of inappropriate statistical analyses, the calculation of numerous significance tests without proper statistical control, the practice of reporting nonsignificant results, and failure to clarify the rationale for excluding particular data sets from certain analyses. Regardless of how powerful a statistical procedure is, however, sophisticated statistical analyses should never be used to try to salvage a weak research design.

\section{GENERALIZABILITY OF RESULTS}

Much of the research on heredity and crime has been conducted on populations outside the United States. Further, the same data base has been used in more than one investigation. Although the repeated use of data obtained primarily from Sweden and Denmark is understandable given the superiority of the recordkeeping systems and accessibility of actual records in these countries, this procedure raises serious questions concerning the generalizability of results because these populations tend to be more culturally, socially, and racially homogeneous than the population of the United States (see Hutchings and Mednick, 1975). Though this homogeneity is advantageous from a research standpoint, it does tend to limit the generalizability of the results to less homogeneous populations.

\section{TRAIT HERITABILITY}

Much of the research on crime and genetics seems to treat heritability as a dichotomous, rather than continuous, variable. A continuous model, however, probably more accurately reflects how most traits are inherited. Reich et al. (1975), in developing a multifactorial model of disease transmission, highlighted the importance of threshold traits in defining one's liability to various psychiatric disorders. They went on to state that multiple thresholds are in many cases more effective than a single threshold in uncovering the biological bases of such disorders. Hence, a continuous or semicontinuous genetic model is used in this study to test the crime-gene hypothesis.

In addition to relying on dichotomous models of disease transmission, 
some researchers seem to view concordance rates as a direct measure of heritability. Because concordance rates are not a true measure of association, we have calculated the tetrachoric coefficient of liability for criminality/sociopathy for studies outlined in Tables 1 through 3. These correlations, which were calculated by comparing the concordance and population (or control) base rates (see Figure 1 in Gottesman and Carey, 1983), more accurately represent the continuous model of genetic transmission than does the concordance rate alone.

\section{CURRENT RESEARCH ON HEREDITY AND CRIME}

The research on heredity and crime has been studied using four basic research designs: family studies, twin studies, adoption studies, and studies investigating the interaction between genes and environment. The rationale behind family studies is that since family members share a common genetic heritage, behaviors that are gene-based should correlate more strongly among family members than among nonfamily members. Twin studies derive from the knowledge that monozygotic twins share all of the same genetic material and dizygotic twins share only half of their genetic inheritance. Thus, one would expect to see greater concordance in monozygotic, as compared with dizygotic, twins for traits that are genetically linked. However, because some researchers argue that the environments of monozygotic twins are more similar than the environments of dizygotic twins, hence confusing the naturenurture issue, adoption studies were implemented. The logic behind adoption studies is that there should be greater concordance between children adopted at an early age and their biological parents than between the children and their adoptive parents for behaviors that are inherited. Finally, gene-environment studies examine the interaction between one's genetic constitution and environmental situation.

\section{FAMILY STUDIES}

In one of the first family studies published on criminality, Dugdale (1877) examined criminality in an extended family, the Jukes, and found an arrest history in several generations of blood relatives. There was very little subsequent research in this area until Rath (1914) published his carefully planned pedigree analysis of 98 male recidivists and their relatives. The results of this analysis revealed that there was significantly more criminality in the families of female than male convicts. Since Dugdale and Rath, several additional investigations (i.e., Burt, 1925; Healy and Bronner, 1928; Partridge, 1928) have documented the existence of a relationship between the criminality of parents and offspring. The problem with these and similarly designed studies is that it is impossible to disentangle the relative contributions of genetics and 
environment. To this end, we have evaluated the individual merits and limitations of family studies published within the past 20 years (see Table 1).

Using a somewhat unique design, Robins and her colleagues (Robins and Lewis, 1966; Robins et al., 1975) examined the criminal life patterns of adults randomly sampled from the elementary school records of a large urban school district. These individuals, along with their offspring (18 years of age and older), were interviewed and evaluated for delinquency and arrest histories. Despite the fact that the sample was exclusively black, the possibility of sampling bias is minimal because elementary school, rather than junior or senior high school, records were inspected and subjects were randomly sampled so that nondelinquent, as well as delinquent, subjects were available (thus providing Robins with a control/comparison group). Of interest here is that the results of Robins's research tend to support a familial approach to criminality, regardless of whether the subjects are black or white, male or female.

In a more typical design, Guze et al. (1967) surveyed the families of 93 convicted male felons and found more relatives with diagnoses of sociopathy compared with what would be found in the community at large. These findings, while seemingly supportive of the genetic hypothesis, are limited by the fact that because Guze et al. did not use a control or comparison group, differential attrition may well have accounted for the results obtained. In a later study, Cloninger and Guze (1973) discerned the existence of an even stronger cross-generational link between 86 female felons and 288 first-degree relatives for both a diagnosis of sociopathy and a prior record of arrest. As was the case with the Guze et al. investigation, however, Cloninger and Guze did not include a control group. To further complicate interpretation of the results, the effects of differential mortality were not considered despite the fact that significantly fewer white male relatives were interviewed in comparison with black male, black female, and white female relatives.

Probably the best designed family-genetic research on crime was published as a series of articles by Cloninger, Reich, and Guze (Cloninger et al., 1975a, 1975b; Reich et al., 1975). In one of these articles, Reich et al. (1975) describe a multifactorial model of disease transmission that they applied to data collected on 86 convicted felons and 387 first-degree relatives (Cloninger et al., 1975a). Finding that their data adequately fit the model, the researchers concluded that the liability for developing sociopathy was normally distributed, rather than being an all-or-nothing phenomenon. From these results they further surmised that the transmission of sociopathy was either polygenetic (if biological factors predominate) or cumulative (if environmental factors predominate). In brief, this study lends support to previous research findings that indicate that sociopathy is more prevalent in males than in females, even though the actual pattern of symptomatology fails to differ as a function of either sex or race. 


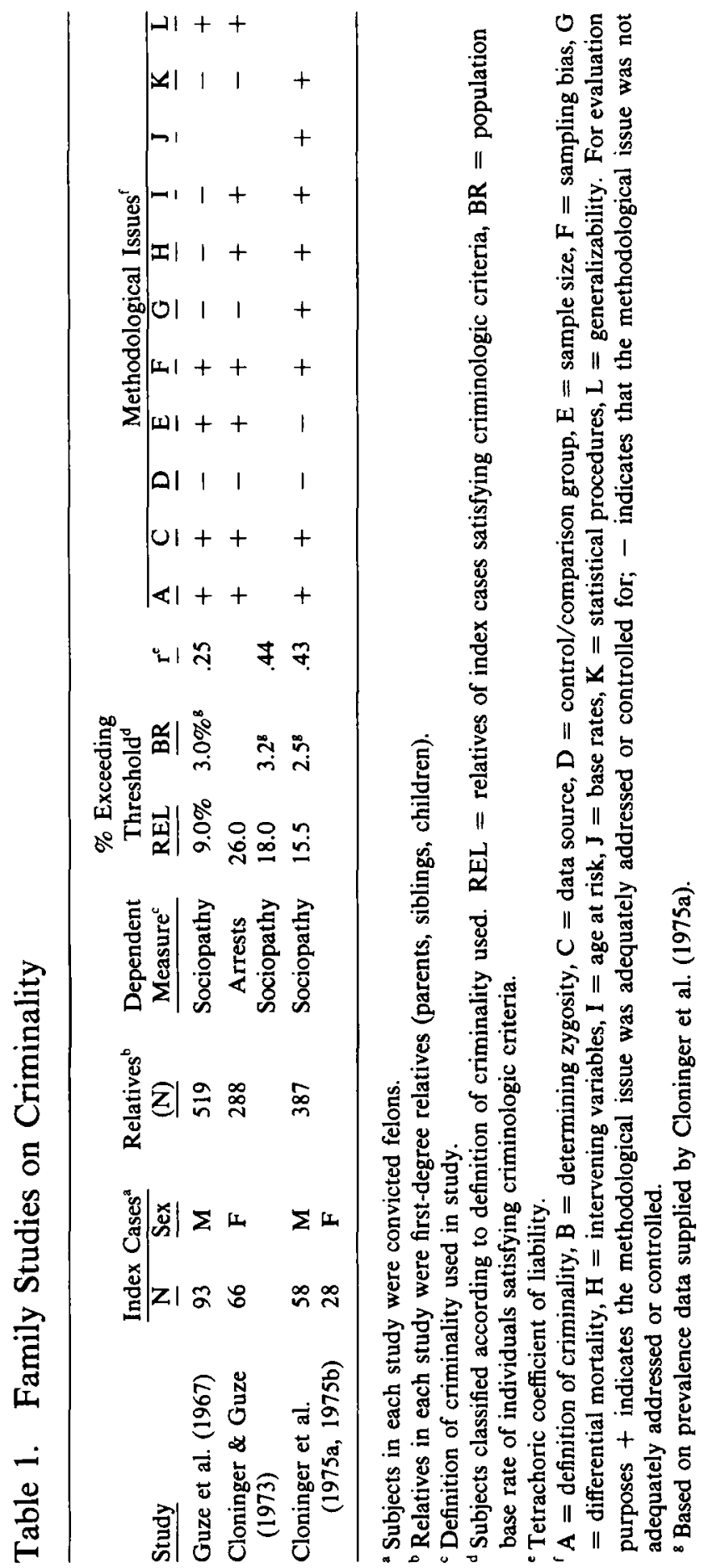


Unmistakably, the family studies reviewed thus far have, for a variety of reasons, been unproductive in isolating the relative contributions of heredity and environment in the development of later criminality. Even though the size and composition of the samples used were adequate, there were several very serious and fundamental methodological flaws, such as the lack of appropriate control groups, the existence of differential mortality, and the use of inadequate statistical procedures, all of which limit the practical utility of this research. Still in all, these studies are not without merit because they may be helpful in developing more homogeneous diagnostic categories (Weissman et al., 1986).

Despite the methodological limitations, family research on criminality has conclusively demonstrated that crime frequently follows family lines. This fact is inescapable, regardless of whether genetic or environmental determinants are at work. These family studies thus provide researchers with a wellsupported, consistent body of knowledge that, in turn, can be useful in developing predictive instruments. Recommendations for future research in this area include the use of more sophisticated statistical procedures and comparison groups composed of noncriminal, psychiatric patients to control for the nonspecific effects of general deviancy. Finally, the use of multigenerational pedigree designs may enhance understanding of the familial variables contributing to the development of later criminal behavior (Weissman et al., 1986).

\section{TWIN STUDIES}

Whereas family studies examine heritability from a narrow perspective in that first-degree relatives have approximately half of their genetic inheritance in common, twin studies consider a broader sphere of genetic influence (to include the complex interaction of genes at different loci) because monozygotic twins have all of their genes in common. At least 11 twin studies have been published on adult criminals since Lange's (1930) groundbreaking research in the late 1920s (see Table 2). Although many of the pre1965 twin studies discerned the existence of a relationship between zygosity and crime, this research was plagued by a plethora of methodological problems. ${ }^{2}$

Note that only same-sexed DZ twins are considered in Table 2 so as to minimize the possibility of an $\mathrm{MZ} / \mathrm{DZ}$ difference arising simply on the basis of there being more female subjects in the $\mathrm{DZ}$ condition (see the section above

2. Because we were unable to obtain the following original articles on criminality in twins-Borgstrom, 1939; Kranz, 1936; LeGras, 1932; Slater, 1938; Stumpful, 1936; Tienari, 1963; and Yoshimasu, 1961, information on these studies was gathered through secondary sources (i.e., Christiansen, 1970, 1977; Dalgard and Kringlen, 1976; Rosenthal, 1975; and Slater and Cowie, 1971). 
on base rates for an explanation of the problems associated with using opposite-sexed DZ twin pairs). Regrettably, even with this precaution differential base rates may still have played a role in producing significant $M Z / D Z$ differences in several of these studies. We draw this conclusion based on Christiansen's $(1970,1974)$ observation of more serious criminality, not to mention more frequent incarceration, among $\mathrm{MZ}$ than $\mathrm{DZ}$ twins. It is very possible, then, that several of the $M Z / D Z$ differences noted in Table 2 were due, at least in part, to the fact that the MZ group contained more criminals and thus evidenced a somewhat higher rate of criminality.

Fortunately, researchers have made a number of methodological improvements in twin studies conducted since 1965 . The most significant refinements have been the use of unselected samples and implementation of blood and serum testing in assessing zygosity. In the first of these studies, Christiansen $(1970,1974)$ examined criminality in an unselected sample of Danish twins and found significantly higher concordance on several measures of criminality in $\mathrm{MZ}$, as opposed to DZ, twins (33\% versus $11 \%$ ). Christiansen also found, as had Yoshimasu (1961) before him, that the MZ/DZ discrepancy tends to increase as one employs narrower definitions of criminality (i.e., serious crimes or a life pattern of criminality). In surveying this same sample of Danish twins, Cloninger et al. (1978) found a smaller number of convicted females than males, but noted that female convicts had many more criminal relatives than did male convicts. Both these studies highlight the fact that a number of variables must be considered in calculating and interpreting concordance rates.

Dalgard and Kringlen (1976) found evidence of a relationship between zygosity and criminality, but their $\mathrm{MZ} / \mathrm{DZ}$ differences did not achieve statistical significance, even when a narrow definition of criminality was employed. Not surprisingly, they also found significantly more $\mathrm{MZ}$ than $\mathrm{DZ}$ twins $(82 \%$ versus $36 \%$ ) who reported experiencing a very close emotional relationship and sense of mutual identity with their twin brother or sister. When Dalgard and Kringlen restricted their analyses to twins reporting such closeness, they discovered that the already small MZ/DZ differences (see Table 2) all but disappeared. Concordance in monozygotic twins without a sense of interdependence, however, was actually higher than that found in interdependent monozygotic twins. This finding appears to run counter to Dalgard and Kringlen's argument that $M Z / D Z$ differences in crime are largely a function of the greater mutual identity and interpersonal proximity of monozygotic twins.

Two twin studies with relevance to the issue of heredity and crime have been published within the past several years. Rowe (1983) mailed out questionnaires asking about a wide variety of different delinquent behaviors to a large number of twins in the eighth through twelfth grades. Approximately 


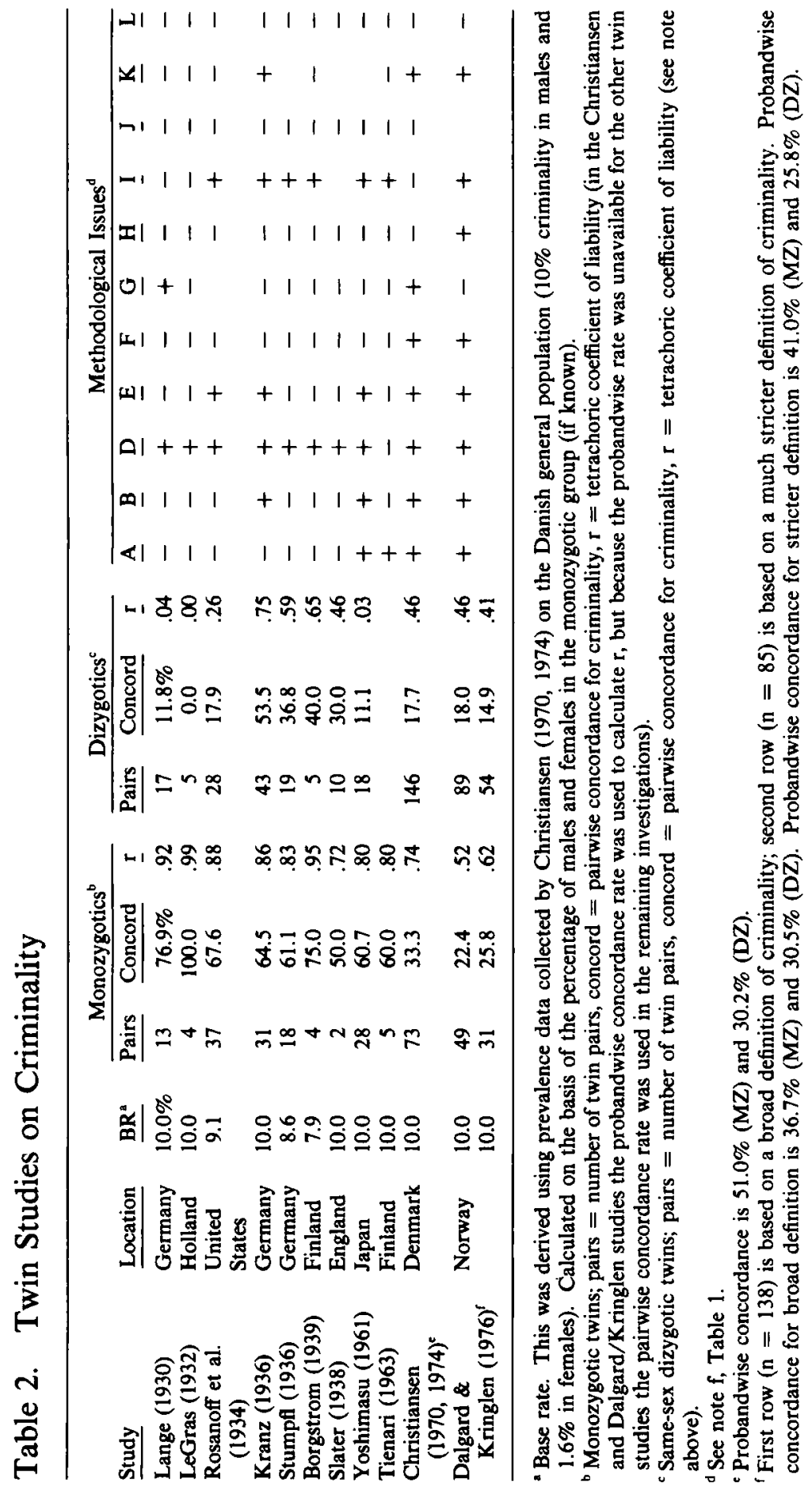


half the questionnaires were returned, and the results suggested that concordance for delinquent behavior was higher in $\mathrm{MZ}$ than $\mathrm{DZ}$ twins. In a study examining the genetic correlates of alcoholism, Gurling et al. (1984) identified criminality in at least 1 member of a group of 29 pairs of twins but found concordance in only 3 pairs ( $1 \mathrm{MZ}, 2 \mathrm{DZ})$.

An issue that often arises with research of this type is whether $M Z$ twins share more similar environments than DZ twins. The research on this topic suggests that $\mathrm{MZ}$ twins are treated more similarly by others and typically spend significantly more time together than $\mathrm{DZ}$ twins (Kidd and Matthysee, 1978; Rosenthal, 1975), although the overall effect of such differential treatment may not be as potent as was once thought (Plomin et al., 1976). In a study of $45 \mathrm{MZ}$ and $37 \mathrm{DZ}$ twin pairs, for instance, Vandenberg (1984) reports that violations of the equal environments assumption do not significantly affect the similarity of various behaviors in twins. Similarly, Wilson (1977) found that the shared experiences of dizygotic twins did not seem to affect the concordance seen in intelligence test scores. In fact, Langinvainio et al. (1984) note that for some traits twins reared apart may be more alike than twins reared together.

In an effort to control for the effects of twinning and mutual identity, Christiansen (1977) examined criminologic data on eight pairs of MZ twins separated during early childhood and found four cases in which there was concordance. Juel-Nielson (1965), on the other hand, compared 12 pairs of Danish MZ twins separated at an early age and discovered that although intelligence was strongly influenced by genetic factors, social-personality characteristics (e.g., social commitment and loyalty) were influenced more by environmental factors. Thus, research on criminality in twins suggests the possibility of at least a qualified relationship between crime and certain genetic characteristics, but it is still difficult to unravel fully the effects of heredity and the environment using a twin methodology.

\section{ADOPTION STUDIES}

One of the more perplexing aspects of current research on crime and heredity is separating the individual contributions of genetics and environment. One of the best ways to overcome a problem such as this would be to study MZ twins raised in different home environments, although as Christiansen (1977) discovered, the occurrence of such cases is so rare that data obtained from these studies are highly idiosyncratic. Consequently, researchers have struck a compromise by studying nontwins who have been adopted away from their biological parents at an early age. This approach, often referred to as the adoption method, would appear to hold promise for answering the nature-nurture question as it relates to criminality. One of the earliest studies (Zur Nieden, 1951) to use this method found virtually no relationship between biological parent and adoptee criminality, although the investigation 
was quite seriously flawed methodologically. More recently, Cadoret et al. (1975) compared adoptees with and without psychiatrically disturbed biological parents and also did not discern a connection between heredity and crime. Although neither of these investigations found support for the genetic hypothesis, it could be argued that more encouraging results might have surfaced had criminality been examined more directly instead of within the context of a general model of behavioral deviance.

Adoption studies taking a more direct approach to the question of crime can be subdivided into two types: the adoptees' family method and the adoptees study method (Rosenthal, 1970). The family method focuses on the relatives of a "criminal" adoptee, whereas the study method considers the adopted offspring of "criminal" biological parents. The results of many of these investigations must be viewed with both caution and skepticism, however, given the serious methodological limitations inherent in the designs used (see Table 3).

The adoptees' family method was used in studies by Schulsinger (1972) and Hutchings and Mednick (1975). Schulsinger, for instance, matched 57 psychopathic adoptees with 57 nonpsychopathic adoptees on such characteristics as age, sex, social class, adoptive age, and early neighborhood environment. He reported that psychopathy was more commonly observed in the relatives of psychopathic adoptees. In a related study, Hutchings and Mednick, sampling from the same group of Danish adoptees as Schulsinger, noted that, relative to the biological fathers of noncriminal control adoptees, biological fathers of criminally convicted probands had a greater history of criminal conviction. These two studies are probably the most widely cited genetic investigations on criminality and have served as an impetus for subsequent adoption studies examining the relationship between heredity and crime.

Using the adoptees study method, Hutchings and Mednick (1975) performed a cross-foster analysis of their data, inspecting the conviction records of adoptees, their biological parents, and their adoptive parents. In effect, they observed $10 \%$ criminality among adoptees whose biological and adoptive parents had no history of criminal conviction, $11.2 \%$ criminality among adoptees with at least one criminal adoptive parent but no criminal biological parent, $21 \%$ criminality among adoptees whose adoptive parents had never been convicted but who had at least one criminally convicted biological parent, and $36.2 \%$ criminality among adoptees with at least one adoptive parent and one biological parent previously convicted.

In a subsequent study, Mednick et al. (1984) used a cross-foster approach to analyze data collected on 14,427 Danish adoptees, including all 1,145 subjects studied by Hutchings and Mednick (1975). Their results were very similar to Hutchings and Mednick's earlier findings; they found conviction rates of $13.5 \%, 14.7 \%, 20.0 \%$, and $24.5 \%$ for adoptees with no criminal parents, a criminal adoptive parent only, a criminal biological parent only, and at least 


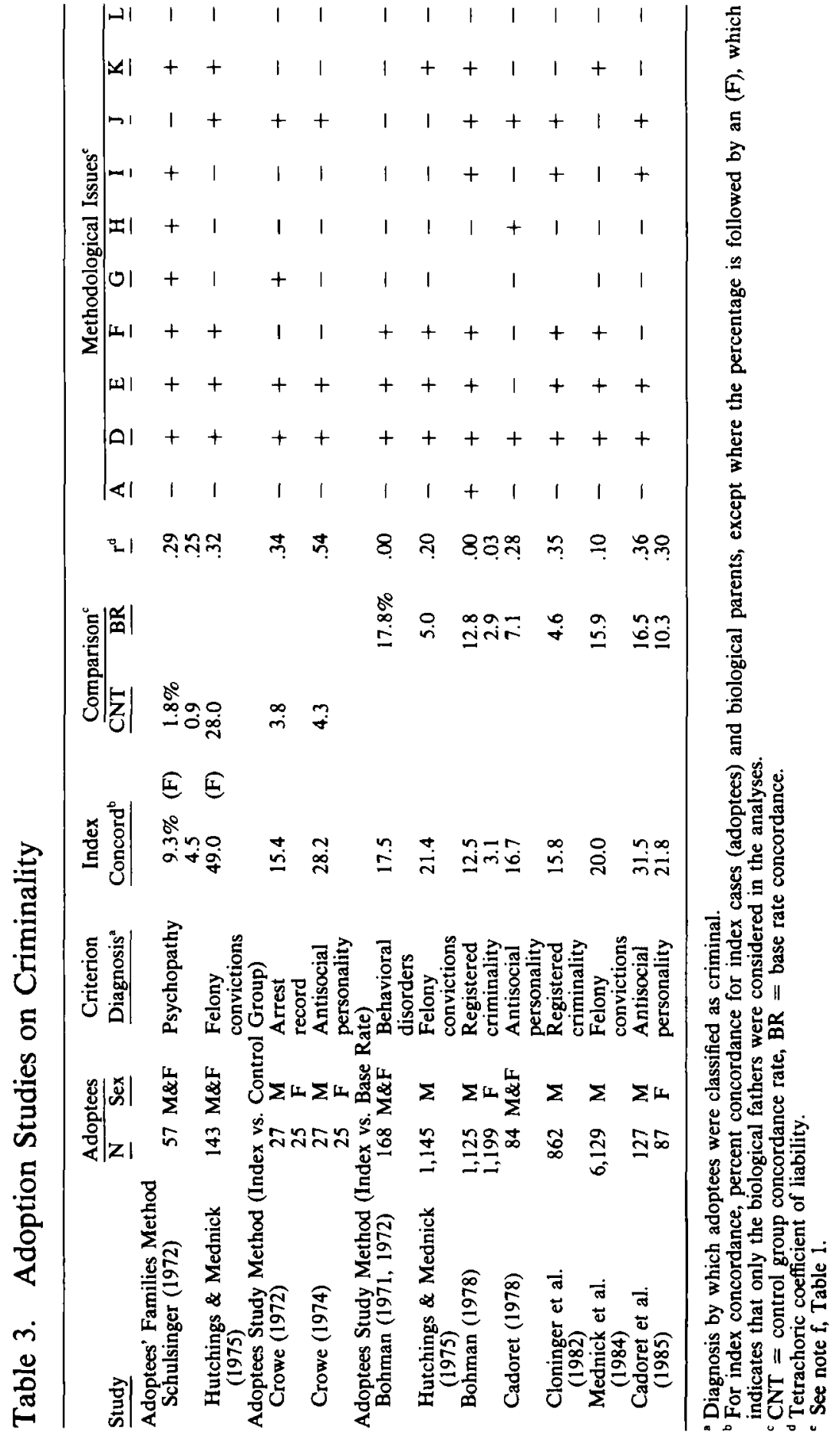


one criminal adoptive parent and one criminal biological parent, respectively. On the surface, then, these data seem to offer support for the proposed criminologic link between biological parents and their offspring.

Inspecting the Mednick et al. (1984) study a bit closer, we found that their support for the genetic hypothesis rests, in part, on the fact that significantly more adoptees with criminal biological parents than without such parents had a record of criminal conviction (20\% versus $13.5 \%$ ). This is in comparison with the criminal adoptive parent-control difference, which was nonsignificant ( $14.7 \%$ versus $13.5 \%)$. To confound matters even further, a large percentage of biological, as opposed to adoptive, parents in both the Mednick et al. (1984) and Hutchings and Mednick (1975) studies had previous criminal convictions. Consequently, the significant findings of these researchers may have actually been artificially inflated by preexisting variations in the base rate of concordance between parents and offspring.

A second group of adoption studies used subjects residing in another West European nation, Sweden. In one of the earliest Swedish studies, Bohman (1972) did not uncover a relationship between biological parent's criminality and behavioral disturbance in adoptees 10 to 11 years old. The lack of positive corroboration of the genetic hypothesis may have been a function, however, of Bohman's use of subjects who had not yet passed through the age of greatest risk for criminal arrest and conviction (i.e., somewhere between the ages of 18 and 25). Six years later, Bohman (1978) shifted the focus of his analysis from delinquency in preadolescents to crime in adults using a large sample of Swedish adoptees who were 25 years of age or older. In this study he observed a correlation between biological parents and adoptees in terms of their alcohol abuse patterns, but as before, no relationship could be found between biological parent and adoptee criminality.

Reanalyzing data from the same Swedish population of adoptees as Bohman (1978), however, a team of investigators (Bohman et al., 1982; Cloninger et al., 1982) found results that suggested that Bohman (1978) may have overlooked an important interaction between alcoholism and criminality. Bohman et al. (1982) argue that when this relationship is taken into account two primary forms of criminality surface, one of which appears genetically linked. The results of subsequent analyses led these investigators to conclude that only property-oriented crime (without alcohol abuse) was genetically based. In a third study using this same Swedish subject pool, Sigvardsson et al. (1982) discovered that criminality in females paralleled that seen in males, although there was a tendency on the part of female criminals to have a more extensive family history of criminality.

Before continuing, several criticisms of the data analyses made in the Swedish investigations should be considered. First, subjects in these studies were often grouped in apparently arbitrary fashion and subjected to numerous analyses, not all of which are reported in the articles. Moreover, the rationale 
for many of these analyses is either never given or presented in such a manner that it is virtually impossible to follow. Finally, given that a large number of separate analyses were calculated, it is not unreasonable to assume that at least some of the results surfaced simply on the basis of chance.

Each of the adoption studies thus far reviewed suffers from a number of critical methodological and interpretive difficulties that in and of themselves raise serious questions about the validity of the observed results. Moreover, serious questions arise about the generalizability of this research because it was conducted using West European populations, which differ in a number of significant ways from the general population of the United States (Hutchings and Mednick, 1975). Given the greater accessibility and availability of data on adoptive status, parentage, and criminal background in countries like Sweden and Denmark, conducting similar studies in the United States is no small task.

Crowe $(1972,1974)$ was the first researcher to examine the relationship between genetics and crime in a sample of adoptees living in the United States. Using a small, preselected sample of Iowan adoptees who had been separated from their incarcerated biological mothers at an early age, Crowe uncovered several very interesting relationships. Basing his conclusions on arrest records provided by the Iowa Bureau of Criminal Investigation, Crowe (1972) determined that 8 of 52 probands $(15.4 \%)$ had histories of arrest compared with only 2 of 52 control subjects (3.8\%). In a subsequent analysis of these data, Crowe (1974) ascertained that significantly more proband than control adoptees received diagnoses of antisocial personality when a structured diagnostic interview was administered. The combined results were interpreted as confirming the hypothesis that deviant personality characteristics and criminality are genetically predetermined.

Conceding for the moment that Crowe's sample is more representative of criminal populations in the United States than the European samples previously discussed, there are still major problems with the generalizability of his sample since it was small, arbitrarily derived, and potentially biased. Questions also arise when we consider the criteria Crowe used to define criminality in the biological mothers, the length and quality of parenting that occurred prior to adoption, and the degree of criminality in the adoptive family home. In addition, adoptees, as a group, tend to be more deviant and delinquent than many other groups of individuals (Bohman, 1971; Offord et al., 1969). Though such a finding does not necessarily invalidate the results observed in adoptee studies, the influence of adoption on deviancy should at least be considered in interpreting one's results.

Cadoret (1978) administered a structured diagnostic questionnaire to a sample of Iowan adoptees presumably different from the subjects examined 
by Crowe $(1972,1974)$. He reported that antisocial and "antisocial spectrum" diagnoses were significantly more frequent among adoptees whose parents also received diagnoses of antisocial personality. Subsequently, Cadoret et al. (1985) reanalyzed Cadoret's data and found a statistically significant biological parent-offspring association for both antisocial personality and alcoholism. However, unlike Bohman et al. (1982), these researchers found the pattern of liability for antisocial personality and alcoholism to be largely independent. While the concordance between genetics and the diagnostic labels employed by Cadoret et al. appears to exceed chance expectations, this study is also limited by several methodological oversights, not the least of which is the exceedingly small number of subjects contained in many of the research cells.

At this juncture, adoption studies appear to represent the best strategy available for determining the independent contributions of environment and heredity relative to human behavior. Unfortunately, the current body of adoption research serves more to cloud than to clarify the relevant issues. Given the inconsistent findings, statistical inadequacies, and interpretive difficulties, the existing work leaves many of our initial questions unanswered. Perhaps the most fundamental difficulty encountered in research using adoptees is the manner in which criminality has been defined. Although equating diagnoses such as psychopathy or antisocial personality with actual criminality may be justified if these diagnoses have been operationally defined, the antisocial personality diagnoses used in many of the adoption studies have often been inadequate. Cadoret et al. (1985), for instance, defined antisocial personality on the basis of two or more behaviors sampled from a group of disparate actions. Employing these criteria a subject could be classified as antisocial for using "bad language" and breaking curfew or running away from home and "being irresponsible" in spending money. In Schulsinger's (1972) study, one could be classified as an antisocial personality simply on the basis of past alcohol or drug abuse. Criterion measures such as these are too vague, idiosyncratic, and detached from criminal involvement to be very useful in investigating the biological correlates of criminal behavior.

Although one should avoid nebulous diagnostic categories lacking in clinical relevance and operational rigor, using a positive arrest or conviction record may not be much of an improvement. Since criminal activity can vary across a panorama of behavior, from a single incident to a life-style of repeated offenses, the type, quantity, and severity of antisocial conduct used to define criminality can greatly influence the number of people who are eventually classified along these lines. Crowe $(1972,1974)$ studied the criminal offspring of incarcerated women on the assumption that incarcerated women could be accurately classified as criminals. The truth of the matter is that of the 41 incarcerated women in Crowe's sample, 5 had been convicted of prostitution, 3 of desertion, 3 of adultery, 2 of lewdness, and 1 each of bigamy and 
transmitting a venereal disease. One can only speculate about how a more realistic definition of criminality may have influenced Crowe's results. Clearly, however, if more meaningful research in this area is to be forthcoming, it is imperative that a more realistic, operationally defined measure of criminality be developed. Our view is that criminality must be considered within a life-style context similar to the narrow definition of criminality introduced in a study by Dalgard and Kringlen (1976). ${ }^{3}$

Another flaw found in current adoption research on crime relates to the length and quality of parenting prior to adoption. Investigators employing the adoption method should strive to use subjects adopted immediately or very shortly after birth. Unfortunately, this has not always been the case; in fact, many of the adoptees serving as subjects in these studies spent the first few months after births living with their biological mothers. For example, in the Swedish studies (Bohman et al., 1982; Cloninger et al., 1982; Sigvardsson et al., 1982) all of the adoptees were removed from their biological mothers before they were 3 years old; the mean separation age was 8 months. Approximately $50 \%$ of the subjects in Mednick's Danish studies (Hutchings and Mednick, 1975; Mednick et al., 1984), on the other hand, had been separated from their biological mothers within the first several weeks, whereas the other half were separated anywhere from several months to a year after birth. Similarly, half the Iowan adoptees studied by Crowe $(1972,1974)$ has been removed from their natural mothers within the first 6 months, and the other half spent 6 to 18 months with their mothers prior to being separated. Although subjects in Cadoret's Iowan sample (Cadoret, 1978; Cadoret et al., 1985) were apparently separated from their biological mothers at birth, $40 \%$ were not adopted until they were at least 3 months old.

These variations in length of biological parenting prior to adoption do not, in and of themselves, invalidate the reported results, although they do raise serious interpretive questions in light of the positive correlation noted between age at time of adoption and subsequent criminal behavior (Offord et al., 1969). It has also been found that proband subjects are typically separated from their biological mothers at a later age and spend more time in orphanages relative to control subjects, although these differences have not always been statistically significant (cf. Bohman et al., 1982; Cadoret et al., 1985; Crowe, 1974; Mednick et al., 1984; Sigvardsson et al., 1982).

The more general issue of rapid incorporation into the adoptive home environment increases in significance when one examines probands who eventually display criminal behavior. Crowe's (1974) research, for instance, demonstrated that, on average, antisocial probands were separated from their

3. This narrow definition was restricted to antisocial acts which would be considered crimes in most countries and included crimes of violence, sexual assault, and property crimes. 
biological mothers 1 month later, remained in an orphanage 10 months longer, and were placed in an adoptive home 11 months after the control subjects and probands with no subsequent record of antisocial behavior. Such differential relationships tend to cast doubt on the validity of many of the adoption studies investigating the heritability of crime in that this critical variable has rarely been adequately controlled. Further, in studies in which the data were available and numerous other analyses were calculated, no effort was made to examine this phenomenon as an independent variable. Ignoring these data, like many of the other serious oversights by researchers in this area, may have significantly influenced the results attained.

\section{GENE-ENVIRONMENT INTERACTION}

A somewhat different approach to the crime-gene question was taken by researchers examining the possibility of an interaction between one's genetic constitution and environment. This is an important new trend in genetic research on crime for if genetics do play a significant role in the development of a criminal life-style, then it is likely that it exerts its influence in concert with various environmental factors (Ellis, 1982). A study recently carried out by Gabrielli and Mednick (1984) determined that both antisocial biological parentage and urban home environment correlated with adoptee criminality, although these relationships were found to be largely independent and noninteractive. Other gene-environment interaction studies have found similar results.

Employing the same 14,427 Danish adoptees as were used in studies conducted by Gabrielli and Mednick (1984) and Mednick et al. (1984), Van Dusen et al. (1983) probed the interrelationships between the social class of biological and adoptive parents and adoptee criminality. They found that adoptees with felony convictions tended to have parents, biological as well as adoptive, of lower social class origin. They went on to conclude that since the social class of both biological and adoptive parents correlated significantly with adoptee criminality, even when each was considered at different levels of the other, genes as well as environment contribute to the development of criminal behavior. There was a small, yet statistically significant correlation, however, between the social class of biological and adoptive parents $(r=.14)$ because the adoption agency in Denmark had a policy of attempting to match biological and adoptive family environments as much as possible. Thus, we have no way of knowing conclusively whether environmental factors alone accounted for these results because Van Dusen et al. did not examine relative concordance (criminal biological parent versus noncriminal biological parent) at different levels of adoptive parent social class.

Earlier, Cadoret and Cain (1980) had performed a series of multivariate 
statistical analyses on Cadoret's (1978) sample of Iowan adoptees. In a manner similar to Gabrielli and Mednick (1984), Cadoret and Cain found biological as well as environmental correlates of adoptee antisociality, but like Gabrielli and Mednick, they did not find an interaction between the two measures. These two studies also determined that environmental factors appear to play a more influential role in male, as opposed to female, criminality. In a later investigation, Cadoret et al. (1983) determined that the probability of an adoptee's engaging in various antisocial acts was greater when genetic and environmental factors were operating in unison rather than independently.

Rowe and Osgood (1984) have also considered the prospect of an interaction between heredity and one's environment relative to the study of criminal behavior. With the aid of twin data, these two investigators demonstrated that both genetic (MZ/DZ comparisons) and environmental (association with delinquent peers) factors were involved in delinquent outcomes. As with previous gene-environment research, the whole (interaction) was greater than the sum of the individual parts (genes and environment considered independently). In their conclusion, Rowe and Osgood offer an interpretation that researchers investigating the genetic features of criminal behavior should most certainly consider, that is, that a genetic explanation could actually supplement and enrich, rather than abate, current criminological theory.

\section{DISCUSSION}

The study of cause and effect, no matter how elusive and problematic (see Kerlinger, 1973), is one of the cornerstones of scientific inquiry. As such, any effort to identify the causes of crime must first satisfy baseline criteria that imply the existence of a cause and effect relationship. Selltiz et al. (1959) argue that three conditions must be met before one is justified in making statements of a causal nature: (1) the cause and effect variables should covary or correlate; (2) the causal agent should either precede or occur simultaneously with the effect; (3) alternative interpretations of the data should be eliminated as reasonable explanations of the observed results.

If, for the moment, one overlooks the rather significant methodological limitations to much of the genetic research thus far reviewed, the first condition of causality (cause and effect variables should correlate with each other) has been met in that the majority of published studies on heredity and crime reflect the existence of at least a moderate relationship between the two. Inspecting the tetrachoric coefficients of liability in Tables 1 through 3, for instance, we see that most are fairly substantial. In addition, because firstdegree relatives share only half of their genes in common, we must double the correlations found in Tables 1 and 3 (but not 2) in order to achieve an accurate estimate of heritability. Applying the procedure to reasonably sound 
studies (i.e., more +'s than -'s in the methodological critique) reveals a heritability estimate of between 0 and $88 \%$ (median $=66 \%$ ).

Turning to the second test of causality, directionality (causal variable either precedes or occurs simultaneously with the proposed effect), the heredity of crime hypothesis meets the test if we can agree that one's genetic constitution is fully established at birth and that measures thought to mirror genetics are actually assessing this biological predisposition. We must look beyond this simplistic analysis, however, because several of the factors thought by researchers to reflect a genetic origin, such as biological parents' social class (e.g., Van Dusen et al., 1983), may actually reflect a strong environmental influence. This is particularly true given that the genetic aspects of these subject's biological parentage have never been directly assessed. This interpretation of the data is largely conjectural, but it could be that variables hypothesized to reflect a genetic influence are actually an effect rather than a cause of criminal behavior. In any event, the preponderance of data on this point favors the crime-gene hypothesis in the sense that there is no strong evidence to contradict the presumed directionality of the moderate relationship thought to exist between heredity and various indices of criminal involvement.

The confounding of biological and environmental factors is at the heart of the third causal condition (alternative explanations should be thoroughly evaluated and, hopefully, dismissed before accepting the causal hypothesis). Unfortunately, there are several equally plausible alternative explanations of the apparent gene-crime relationship. For instance, Mednick and his colleagues attempted to control for the effects of social class in several of their investigations, but each study reports the existence of a significant correlation between biological and adoptive parents' social class (cf. Hutchings and Mednick, 1975; Van Dusen et al., 1983). Moreover, because the attempts made by Mednick and his co-workers to control for social class differences have been incomplete and largely inadequate, social class cannot be ruled out as a reasonable alternative explanation of the results obtained. More important, although the association between social class and criminality is somewhat controversial (see Tittle et al., 1978), a wealth of empirical information suggests that there is at least a qualified relationship between these two variables (see Braithwaite, 1981).

Another alternative interpretation of the genetic-crime data relates to the early developmental experiences of subjects. Although MZ twins were found to display greater concordance for criminality than $\mathrm{DZ}$ twins, this does not rule out an environmental explanation because the observed relationship may have been the product of a greater sense of mutual identity and attachment on the part of MZ twins (see Dalgard and Kringlen, 1976). Similarly, data from several of the adoption studies suggest that the association between biological parent and offspring criminality may have been partially a function of 
the amount of time adoptees spent either with their biological mothers (Crowe, 1974; Sigvardsson et al., 1982) or in an orphanage (Crowe, 1974; Mednick et al., 1984) because increased levels of criminality were associated with changes in both variables. Most adoption studies also fail to consider the effects of labeling-adoptive status itself may have exerted a labeling effect on the subjects in several of these investigations.

A third possibility is that intelligence, which has been shown to have clear genetic correlates (Bouchard and McGue, 1981; Scarr and Weinberg, 1977), may have played an intervening role in the gene-crime relationship. West and Farrington (1973), for instance, determined that convicted juveniles achieved significantly lower IQ scores than nonconvicted youths, and Manne et al. (1962) found lower IQs in adult offenders than in the population at large. It may not even be that less intelligent individuals commit more crimes, they may simply tend to engage in crimes that are more impulsive, easier to detect, and more likely to result in arrest (Wilson and Herrnstein, 1985). Although these alternative explanations may not be any more valid than the genetic hypothesis, and some (like the intelligence explanation) may in fact be compatible with a genetic interpretation of criminal behavior, they still lead us to question the robustness of the crime-gene connection relative to the third test of causality and should therefore be addressed in future research investigations.

\section{CONCLUSION}

Returning now to our original question, whether the observed relationship between heredity and crime is a function of bad genes or bad research, we offer the following general conclusion. Genetic factors are undoubtedly correlated with various measures of criminality, but the large number of methodological flaws and limitations in the research should make one cautious in drawing any causal inferences at this point in time. Our review leads us to the inevitable conclusion that current genetic research on crime has been poorly designed, ambiguously reported, and exceedingly inadequate in addressing the relevant issues. This criticism applies to studies that are generally supportive of the crime-heredity hypothesis as well as to studies that fail to substantiate the basic tenets of the genetic argument. Perhaps even more significant, however, these studies have muddied the already turbid waters of genetic research on crime.

To clarify genetic research on crime, greater precision is necessary, starting with the use of criterion measures that are more meaningful, replicable, and substantially narrower than the ones currently being employed. The time has come to abandon global estimates of criminality in favor of measures that are stable, meaningful, and behaviorally referenced. Hare's (1980) Psychopathy Checklist is as a model of how a more precise definition of criminality can be 
achieved. In addition to being more reliable than global measures, narrower definitions of criminality have been found to yield stronger estimates of familial influence than more global definitions (cf. Christiansen, 1974; Dalgard and Kringlen, 1976). The debate concerning whether to employ official or selfreport measures in studies on crime is far from being resolved, although the results of several investigations show that self-report scales are capable of providing valuable information on the presumed nexus between heredity and crime (see Rowe, 1983).

Researchers also need to eliminate alternative explanations of their findings by controlling for important intervening and confounding variables, such as social class, intelligence, and time spent with the natural mother prior to adoption. Such variables should be integrated into future research designs so that their effect on the crime-heredity connection can be investigated. More sophisticated designs, such as the longitudinal/cross-situation model used to study temporal stability, cross-situational consistency, and longitudinal change of genetically mediated personality characteristics (Rowe, 1987), should also be implemented. Finally, genetic research on crime must be better organized theoretically.

In regard to this last recommendation, one gets the impression after reviewing the genetic research on crime that, except for a few isolated studies (e.g., Reich et al., 1975), the data on this subject are devoid of theoretical structure and organization. In developing a meaningful conceptual framework for research findings being collected on the issue of heredity and crime, it is essential that one first understand which of the many behavioral characteristics found in criminal offenders may be influenced by heredity. Nonspecific factors, like general intelligence and temperament, and physiological factors that predispose one to later criminality have both been implicated as important in this regard (see Van Dusen et al., 1983). Conceptualizing these variables as risk factors that facilitate, rather than determine, the development of later criminality may provide the theoretical structure so sorely missing in this area of endeavor. Until methodological improvements are made and a coherent theoretical framework found, however, little progress is anticipated in the effort to determine whether genes play a meaningful role in the evolution of criminal behavior.

\section{REFERENCES}

Bohman, Michael

1971 A comparative study of adopted children, foster children and children in their biological environment born after undesired pregnancies. Acta Paediatrica Scandinavica 60 (Supp. 221):5-38.

1972 A study of adopted children, their background, environment and adjustment. Acta Paediatrica Scandinavica 61:90-97. 
1978 Some genetic aspects of alcoholism and criminality: A population of adoptees. Archives of General Psychiatry 35:269-276.

Bohman, Michael, C. Robert Cloninger, Sören Sigvardsson, and Anne-Liis von Knorring

1982 Predisposition to petty criminality in Swedish adoptees: I. Genetic and environmental heterogeneity. Archives of General Psychiatry 39:1233-1241.

Borgstrom, C.A.

1939 Eine serie von Kriminellen zwilligen. Archiv fur Rassen-und Gesellschaftsbiologie 33:334-343.

Bouchard, Thomas J. and Matthew McGue

1981 Familial studies of intelligence: A review. Science 212:1055-1958.

Braithwaite, John

1981 The myth of social class and criminality reconsidered. American Sociological Review 46:36-57.

Burt, Cyril

1925 The Young Delinquent. New York: Appleton \& Co.

Cadoret, Remi J.

1978 Psychopathology in adopted away offspring of biologic parents with antisocial behavior. Archives of General Psychiatry 35:176-184.

Cadoret, Remi J. and Colleen Cain

1980 Sex differences in predictors of antisocial behavior in adoptees. Archives of General Psychiatry 37:1171-1175.

Cadoret, Remi J., Lynn Cunningham, Rosemary Loftus, and James Edwards

1975 Studies of adoptees from psychiatrically disturbed biologic parents: II.

Temperament, hyperactive, antisocial, and developmental variables. Journal of Pediatrics 87:301-306.

Cadoret, Remi J., Colleen Cain, and Raymond R. Crowe

1983 Evidence for a gene-environment interaction in the development of adolescent antisocial behavior. Behavior Genetics 13:301-310.

Cadoret, Remi J., Thomas O'Gorman, Ed Troughton, and Ellen Heywood

1985 Alcoholism and antisocial personality: Interrelationships, genetic and environmental factors. Archives of General Psychiatry 42:161-167.

Christiansen, Karl O.

1970 Crime in a Danish twin population. Acta Geneticae Medicae Gemellologiae: Twin Research 19:323-326.

1974 Seriousness of criminality and concordance among Danish twins. In R. Hood (ed.), Crime, Criminology, and Public Policy. London: Heinemann.

1977 A review of studies of criminality among twins. In Sarnoff A. Mednick \& Karl O. Christiansen (eds.), Biosocial Bases of Criminal Behavior. New York: Gardner Press.

Cloninger, C. Robert and Samuel B. Guze

1973 Psychiatric illness in the families of female criminals: A study of 288 firstdegree relatives. British Journal of Psychiatry 122:697-703.

Cloninger, C. Robert, Theodore Reich, and Samuel B. Guze

1975a The multifactorial model of disease transmission: II. Sex differences in the familial transmission of sociopathy (antisocial personality). British Journal of Psychiatry 127:11-22. 
1975b The multifactorial model of disease transmission: III. Familial relationships between sociopathy and hysteria (Briquet's syndrome). British Journal of Psychiatry 127:23-32.

Cloninger, C. Robert, Karl O. Christiansen, Theodore Reich, and Irving I. Gottesman 1978 Implications of sex differences in the prevalences of antisocial personality, alcoholism, and criminality for familial transmission. Archives of General Psychiatry 35:941-951.

Cloninger, C. Robert, Sören Sigvardsson, Michael Bohman, and Anne-Liis von Knorring

1982 Predisposition to petty criminality in Swedish adoptees: II. Cross-fostering analysis of gene-environment interaction. Archives of General Psychiatry 39:1242-1247.

Crowe, Raymond $\mathbf{R}$.

1972 The adopted offspring of women criminal offenders: A study of their arrest records. Archives of General Psychiatry 27:600-603.

1974 An adoption study of antisocial personality. Archives of General Psychiatry 31:785-791.

Dalgard, Odd S. and Einar Kringlen

1976 A Norwegian twin study of criminality. British Journal of Criminology 16:213-232.

Dugdale, Robert L.

1877 The Jukes: A Study in Crime, Pauperism, Disease, and Heredity. New York: G.P. Putnam's Sons.

Dworkin, Robert H., Barbara W. Burke, Brendan A. Maher, and Irving I. Gottesman 1976 A longitudinal study of the genetics of personality. Journal of Personality and Social Psychology 34:510-518.

Ellis, Lee

1982 Genetics and criminal behavior. Criminology 20:43-66.

Flanagan, Timothy J. and Edmund McGarrell (eds.)

1986 Sourcebook of Criminal Justice Statistics-1985. Washington, D.C. Government Printing Office.

Gabrielli, William and Sarnoff A. Mednick

1984 Urban environment, genetics, and crime. Criminology 22:645-652.

Goldsmith, H.H.

1983 Genetic influences on personality from infancy to adulthood. Child Development 54:331-355.

Gottesman, Irving I. and Gregory Carey

1983 Extracting meaning and direction from twin data. Psychiatric Developments $1: 35-50$.

Gurling, H.M.D., B.E. Oppenheim, and R.M. Murray

1984 Depression, criminality and psychopathology associated with alcoholism: Evidence from a twin study. Acta Geneticae Medicae Gemellologiae: Twin Research 33:333-339.

Guze, Samuel B., Edwin D. Wolfgram, Joe K. McKinney, and Dennis P. Cantwell

1967 Psychiatric illness in the families of convicted criminals: A study of 519 first-degree relatives. Diseases of the Nervous System 28:651-659. 
Hare, Robert D.

1980 A research scale for the assessment of psychopathy in criminal populations. Personality and Individual Differences 1:111-119.

Healy, William and August F. Bronner

1926 Delinquents and Criminals: Their Making and Unmaking. New York: Macmillan.

Hutchings, Barry and Sarnoff A. Mednick

1975 Registered criminality in the adoptive and biological parents of registered male criminal adoptees. In R.R. Fieve, D. Rosenthal, and H. Brill (eds.), Genetic Research in Psychiatry. Baltimore: John Hopkins University Press.

Jarvik, Lissey F., Victor Klodin, and Steven S. Matsuyama

1973 Human aggression and the extra Y chromosome: Fact or fantasy? American Psychologist 28:674-682.

Juel-Nielsen, Niels

1965 Individual and Environment: A Psychiatric-Psychological Investigation of Twins Reared Apart. Copenhagen: Nunksgaard.

Kerlinger, Fred N.

1973 Foundations of Behavioral Research. 2nd ed. New York: Holt, Rinehart \& Winston.

Kidd, Kenneth K. and Steven Matthysee

1978 Research designs for the study of gene-environment interactions in psychiatric disorders: Report of a Foundations Fund for Research in Psychiatry panel. Archives of General Psychiatry 35:925-932.

Klein, Malcolm W.

1987 Watch out for that last variable. In Sarnoff A. Mednick, Terrie E. Moffitt, and Susan A. Stack (eds.), The Causes of Crime: New Biological Approaches. New York: Cambridge University Press.

Kranz, Heinrich

1936 Lebenschieksale Krimineller Zwillinge. Berlin: Springer-Verlag.

Lange, Johannes

1930 Crime and Destiny (trans. C. Haldane). 1929. New York: Charles Boni.

Langinvainio, H., J. Kaprio, M. Koskenvuo, and J. Loanqvist

1984 Finnish twins reared apart: III. Personality factors. Acta Geneticae

Medicae et Gemellologiae: Twin Research 33:259-264.

LeGras, Auguste M.

1932 Psychose en Criminaliteit bij Tweelingen. Utrecht: University of Utrecht.

Loehlin, John C., Lee Willerman, and Joseph M. Horn

1985 Personality resemblances in adoptive families when children are lateadolescent or adult. Journal of Personality and Social Psychology 48:376-392.

Lombroso, Cesare

1978 Crime, its Causes and Remedies. Boston: Little Brown.

Manne, Sigmund H., A. Kandel, and David Rosenthal.

1962 Differences between performance IQ and verbal IQ in a severely sociopathic population. Journal of Clinical Psychology 18:73-77. 
Mednick, Sarnoff A.

1987 Introduction-Biological factors in crime causation: The reactions of social scientists. In Sarnoff A. Mednick, Terrie E. Moffitt, and Susan A. Stack (eds.), The Causes of Crime: New Biological Approaches. New York: Cambridge University Press.

Mednick, Sarnoff A., William F. Gabrielli, and Barry Hutchings

1984 Genetic influence in criminal convictions: Evidence from an adoption cohort. Section 224:891-894.

Meehl, Paul E. and Albert Rosen

1955 Antecedent probability and the efficacy of psychometric signs, patterns, or cutting scores. Psychological Bulletin 52:194-216.

Nichols, R.C. and W.C. Bilbro

1966 The diagnosis of twin zygosity. Acta Genetica 16:265-275.

Offord, D.R., J.F. Aponte, and L.A. Cross

1969 Presenting symptomatology of adopted children. Archives of General Psychiatry 20:110-116.

Owen, David R.

1972 The 47, XYY male: A review. Psychological Bulletin 78:209-233.

Partridge, G.E.

1928 A study of 50 cases of psychopathic personality. American Journal of Psychiatry 7:953-973.

Plomin, Robert, Lee Willerman, and John C. Loehlin

1976 Resemblance in appearance and the equal environments assumption in twin studies of personality traits. Behavior Genetics 6:43-52.

Rath, Carl

1914 Uber die Verebung von Dispositionem zum Verbrechen: Eine Statistische und Psychologische Untersuchung. Stuttgart: C. Rath.

Reich, Theodore, C. Robert Cloninger, and Samuel B. Guze

1975 The multifactorial model of disease transmission: I. Description of the model and its use in psychiatry. British Journal of Psychiatry 127:1-10.

Robins, Lee N. and Ruth G. Lewis

1966 The role of the antisocial family in school completion and delinquency: A three-generation study. Sociological Quarterly 7:500-514.

Robins, Lee N., Patricia A. West, and Barbara L. Herjanic

1975 Arrests and delinquency in two generations: A study of black urban families and their children. Journal of Child Psychology and Psychiatry 16:125-140.

Rosanoff, Aaron J., Leva M. Handy, and Isabel A. Rosanoff

1934 Criminality and delinquency in twins. Journal of Criminal Law and Criminology 24:923-934.

Rosenthal, David

1970 Genetic Theory and Abnormal Behavior. New York: McGraw Hill.

1975 Heredity in criminality. Criminal Justice and Behavior 2:3-21.

Rowe, David C.

1983 Biometrical genetic models of self-reported delinquent behavior: A twin study. Behavior Genetics 13:473-489. 
1987 Resolving the person-situation debate: Invitation to an interdisciplinary dialogue. American Psychologist 42:218-227.

Rowe, David C. and D. Wayne Osgood

1984 Heredity and sociological theories of delinquency: A reconsideration.

American Sociological Review 49:526-540.

Rushton, J. Philippe, Robin J.H. Russell, and Pamela A. Wells

1985 Personality and genetic similarity theory. Journal of Social and Biological Structures 8:63-86.

Rushton, J. Philippe, David W. Fulker, Michael C. Neale, David K. Nias, and Hans J. Eysenck

1986 Altruism and aggression: The heritability of individual differences. Journal of Personality and Social Psychology 50:1192-1198.

Sandberg, A.A., G.F. Koepf, T. Ishihara, and T.S. Hauschka

1961 XYY human male. Lancet 2:488-489.

Scarr, Sandra and Richard A. Weinberg

1977 Intellectual similarities within families of both adopted biological children. Intelligence 1:170-191.

Schulsinger, Fini

1972 Psychopathy: Heredity and environment. International Journal of Mental Health 1:190-206.

Selltiz, Claire, Marie Jahoda, Morton Deutch, and Stuart W. Cook

1959 Research Methods in Social Relations. Rev. ed. New York: Holt.

Sheldon, William

1942 The Varieties of Temperament: A Psychology of Constitutional Differences. New York: Harper \& Row.

Siemens, Hermann W.

1924 Die Zwillingpathologie, Ihre Bedeutung, Ihre Methodik, Ihre Bisherigen Ergebnisse. Berlin: Springer.

Sigvardsson, Sören, C. Robert Cloninger, Michael Bohman, and Anne-Liis von Knorring

1982 Predisposition to petty criminality in Swedish adoptees: III. Sex differences and validation of the male typology. Archives of General Psychiatry 39:1248-1253.

Slater, Eliot

1938 Zur Erbpathologie des manisch-depressiven Irreseins. Die Eltern und Kinder von Manisch-Depressiven. Zeitschrift fuer die Gesamte Neurologie und Psychiatrie 163:1-147.

Slater, Eliot and Valerie Cowie

1971 The Genetics of Mental Disorders. London: Oxford University Press.

Stumpful, Friedrich

1936 Die Ursprunge des Verbrechens am Lebenslauf von Zwillingen. Leipzig:

Georg Thieme Verlag.

Sutherland, Edwin $\mathrm{H}$.

1951 Critique of Sheldon's "Variety of Delinquent Youth." American Sociological Review 16:10-13. 
Tienari, Pekka

1963 Psychiatric illnesses in identical twins. Acta Psychiatric Scandinavica 39 (Suppl. 171).

Tittle, Charles R., Wayne J. Villemez, and Douglas A. Smith

1978 The myth of social class and criminality: An empirical assessment of the empirical evidence. American Sociological Review 43:643-656.

Vandenberg, Steven G.

1984 Does a special twin situation contribute to similarity for abilities in MZ and DZ twins? Acta Geneticae Medicae et Gemellologiae: Twin Research 33:219-222.

Van Dusen, Katherine T., Sarnoff A. Mednick, William F. Gabrielli, and Barry Hutchings

1983 Social class and crime in an adoption cohort. Journal of Criminal Law and Criminology 74:249-269.

Weissman, Myrna M., Kathleen R. Merikangas, Karen John, Priya Wickramaratne, Brigitte A. Prusoff, and Kenneth K. Kidd

1986 Family-genetic studies of psychiatric disorder: Developing technologies. Archives of General Psychiatry 43:1104-1116.

West, Donald J. and David P. Farrington

1973 Who Becomes Delinquent? London: Heinemann.

Wilson, James Q. and Richard J. Herrnstein

1985 Crime and Human Nature. New York: Simon \& Schuster.

Wilson, Ronald $\mathbf{S}$.

1977 Twins and siblings: Concordance for school-age mental development. Child Development 48:211-216.

Wirt, Robert D. and Peter F. Briggs

1965 The meaning of delinquency. In Herbert C. Quay (ed.), Juvenile Delinquency. Princeton, N.J.: Van Nostrand.

Yochelson, Samuel and Stanton E. Samenow

1976 The Criminal Personality. Vol. I. A Profile for Change. New York: Jason Aronson.

Yoshimasu, Shûfu

1961 The criminological significance of the family in the light of the studies of criminal twins. Acta Criminologiae et Medicinae Legalis Japanica 27:117-141.

Zur Nieden, Margarete

1951 The influence of constitution and environment upon the development of adopted children. Journal of Psychology 31:91-95.

Glenn D. Walters is Staff Psychologist at the U.S. Penitentiary, Leavenworth, Kansas. His research interests include use of personality assessment procedures, like the Minnesota Multiphasic Personality Inventory, with offender populations and the development of a theory of lifestyle criminality.

Thomas W. White is the Chief of Psychology Services at the U.S. Penitentiary, Leavenworth, Kansas. His interests center on correctional administrative issues. 